JMIAP

jmiap.ppj.unp.ac.id
Email : jianfis.unp@gmail.com

Vol. 2 No. 1 Maret 2019

\title{
IMPLEMENTASI PROGRAM BANTUAN PANGAN NON TUNAI (BPNT) DI KECAMATAN KURANJI KOTA PADANG
}

\author{
M. Hidayat Panuntun Muslim, \\ Jurusan Administrasi Publi, Fakultas Ilmu Sosial Universitas Negeri Padang \\ email: panuntunmuslim@gmail.com \\ Dra, Fitri Eriyanti, dan Adil Mubarak S.IP, M.Si \\ Jurusan Administrasi Publi, Fakultas Ilmu Sosial Universitas Negeri Padang \\ Email: $\underline{\text { itri.eriyanti4138@gmail.com adilmubarak08@gmail.com }}$
}

\begin{abstract}
This study aims to describe how the implementation of the Non-Cash Food Assistance (BPNT) program in Kuranji Sub-District, Padang City. The background of the problem in this study is that based on preliminary observations, BPNT is assistance provided by the government to alleviate poverty and prosper the families of beneficiaries of the assistance. The large number of people who do not understand and appreciate the government's commitment has made this program not running well. The type and data analysis uses a descriptive qualitative approach. Data sources consist of primary data in the form of a direct interview process and secondary data is data collected from the institutional literature related to this research. The technique of collecting data uses

observation, interviews and documentation. Test the validity of the

data using the data source triangulation technique. And data collection techniques with data reduction techniques, data presentation and conclusion drawing. The results of this study indicate that the implementation of the BPN program has not gone well because there are obstacles in the lower level government that have not optimized the BPN implementation smoothly. Many people do not know the process and there are still many underprivileged people who are not registered to receive the assistance.
\end{abstract}

keyword: implementation, decision bpnt

M. Hidayat Panuntun Muslim, Dra. Fitri Eriyanti, Adil Mubarak, S.IP., M. Si. $\mid 60$

IMPLEMENTASI PROGRAM BANTUAN PANGAN NON TUNAI (BPNT) DI KECAMATAN KURANJI 


\section{Pendahuluan}

Pada tahun 2017 Beras Sejahtera (Rastra) tidak lagi dijalankan sepenuhnya di Indonesia, hanya dijalankan pada beberapa kabupaten/ kota di Indonesia. Karena program tersebut sudah digantikan dengan program baru yakni, Bantuan Pangan Non Tunai (BPNT) yang diujicobakan ke 44 Kabupaten/kota pada tahun 2017 yang memiliki akses dan fasilitas yang memadai.

Menurut Pedoman Umum BPNT 2018 berdasarkan Peraturan Presiden Republik Indonesia Nomor 63 Tahun 2017 tentang Penyaluran Bantuan Sosial Secara Non Tunai, bantuan pangan non tunai adalah bantuan sosial pangan yang disalurkan dalam bentuk non tunai dari pemerintah yang diberikan kepada Keluarga Penerima Manfaat (KPM) setiap bulannya melalui mekanisme uang elektronik yang digunakan untuk hanya membeli bahan pangan di pedagang bahan pangan atau yang disebut $E$-Warong yang bekerjasama dengan bank penyalur.

Tujuan dari program BPNT dalam pedoman umum adalah mengurangi beban pengeluaran KPM melalui pemenuhan sebagian kebutuhan pangan; memberikan gizi yang lebih seimbang kepada KPM; meningkatkan ketetapan sasaran dan waktu penerimaan bantuan pangan bagi KPM; memberikan pilihan dan kendali kepada KPM dalam memenuhi kebutuhan pangan; dan mendorong pencapaian tujuan Pembangunan Berkelanjutan (Suistanable Develompment Goals/SDGs)(pedoman umum BPNT 2018).

Berdasarkan data yang diketahui bahwa tidak adanya pemerataan pendataan serta mekanisme pendataan yang tidak relevan dengan data lapangan.Bisa dilihat bahwa kurangnya pengetahuan masyarakat tentang pendataan program tersebut sehingga menimbulkan pertanyaan serta kebingungan di tengah masyarakat.Selama ini masyarakat hanya mengetahui Beras miskin atau Beras Sejahtera di peruntukkan untuk masyarakat kurang mampu, tetapi kenyataanya tidak hanya masyarakat kurang yang mendapatkan bantuan tersebut.namun juga masyarakat yang tergolong mampu mendapatkan bantuan tersebut.Berikut data masyarakat penerima bantuan yang berasal dari masyarakatkurang mampudi Kelurahan Kuranji Kecamatan.Kuranji

Diketahui bahwa jumlah masyarakat kurang mampu sebanyak 1.198 KK, sedangkan masyarakat yang menerima bantuan sebanyak $451 \mathrm{KK}$ pada tahun 2017.Berarti ada sekitar 747 KK yang seharusnya juga berhak menerima bantuan tapi tidak terdaftar dalam penerima bantuan. Seperti halnya data terakhir penulis temukan di lapangan dalam daftar nama penerima BPNT APBD tahun 2018 hanya sebanyak $65 \mathrm{KK}$ yang diusulkan.

Berdasarkan kondisi dari hasil wawancara dan pengamatan penelitidiatas maka dari pada itu peneliti tertarik untuk melakukan penelitian dengan judul "Implementasi Program Bantuan Pangan Non Tunai (BPNT) di Kecamatan Kuranji Kota Padang”

\section{KAJIAN KEPUSTAKAAN}

\section{Konsep Kebijakan Publik}

Menurut Friedrich (Winarno, 2007) memandang kebijakan menjadi suatu arah tindakan yang diusulkan oleh seseorang.Kelompok atau pemerintah dalam suatu lingkungabagn tertentu yang memberikan hambatan-hambatan peluangpeluang terhadap kebijakan - kebijakan yang diusulkan untuk menggunakan dan 
mengatasi dalam rangka mencapai suatu tujuan atau merealisasikan suatu sasaran atau maksud tertentu. Sedangkan Eystone (Wahab, 2015) menjelaskan bahwa kebijakan publik adalah "the relationship of governmental unit to its environment " (antar hubungan yang berlangsung diantara unit/satuan pemerintahan dengan lingkungannya).

Pengertian kebijakan yang di maksud oleh Friedrich mengarah kepada tindakan yang diberikan oleh kelomok dalam hal menentukan sikap untuk mengatasi hambatan-hambatan atas kebijakan yang telah diusulkan sebelumnya.Pendapat yang dikemukakan oleh Friedrich selaras dengan pendapat yang dikemukakan oleh Esytonen, yakni adanya hubungan-hubungan tertentu dalam lingkungan pemerintah antara uni/satuan dalam mengatasi hambatan dalam realisasi kebijakan.

Kebijakan publik sebagai ranah dalam penyelesaian masalah publik seringkali menjadi harapan bagi berbagai pihak.Dengan adanya kebijkan publik dapat mengembalikan eksistensi dari sektor publik agar dapat bergerak lebih cepat dari pada sebelumnya.Ini semua tentu tidak hanya sekedar membutuhkan aktor pemerintah ataupun poltik namun berbagai lapisan masyarakat yang ada sehingga penyelengaraan untuk menyelesaikan masalah publik dapat terlaksana secara rasional dan diterima diterima oleh berbagai kelompok kepentingan yang terlibat.

\section{Konsep Implementasi Kebijakan}

Implementasi kebijkan dalam arti seluas- luasnya sering dianggap sebagai pengoperasionalisasian atau penyelenggaraan aktivitas yang telah ditetapkan berdasarkan undang-undang dan menjadi kesepakatan bersama diantara beragam pemangku kepentingan (stakeholders), aktor, organisasi (publik atau privat) prosedur, dan teknik secara sinergitas yang digerakkan untuk bekerjasama guna menerapkan kebijakan kearah terrentu yang dikehendaki. Rasionalitas atau ulasan di balik langkah seperti ini tak lain dimaksudkan agar sikap, prilaku, dan pikiran dari semua pemangku kepentingan yang terlibat dapat lebih terkontrol serta tetap terjaga pada relnya (Wahab, 2015)

Dalam arti luas penyelenggaraan kebijakan harus berdasarkan undangundang serta menjadi kesepakatan bersama berbagai pemangku kepentingan. Implementasi kebijakan yang dimaksud harus berada pada sinergitas yang selalu bekerjasama anta pemangku kepentingan dan pihak lain guna menerapkan kebijakan kearah yang dikehendaki. Sehingga sikap, prilaku dan pikiran semua yang terlibat dapat terkontrol secara baik.

Jadi menurut beberapa ahli yang mengemukakan pendapatnya diatas dapat diambil kesimpulan bahwa implementasi kebijakan adalah suatu tindakan yang dilakukan oleh implementator dalam mencapai tujuan-tujuan yang hendak dicapai dari sebuah kebijakan. Kebijakan itu dapat berupa mengorganisir,menginpresentasikan dan menetapkan kebijkan yang telah diseleksi, serta memerlukan sumber daya yang mendukung. Implementasi juga dapat dikatakan sebagai tahap pelaksanaan dari aturan-aturan atau kebijkan yang dibuat oleh pemerintah atau aktor kebijakan.

\section{METODE PENELITIAN}

Metode penelitian yang digunakan adalah kualitatif dengan pendekatan deskriptif. Lokasi yang digunakan dan tempat penelitian adalah di wilayah Kecamatan Kuranji.. Informan yang 
digunakan dalam penelitian iani adalah merupakan pihak yang memiliki informasi lengkap sesuai kebutuhan peneliti. Berdasarkan penelitian ini menjelaskan tentang Impementasi Program Bantuan Pangan Non Tunai (BPNT).

\section{HASIL DAN DISKUSI}

Sesuai dengan temuan penelitian, maka pada bagian ini akan dijelaskan Implementasi Program Bantuan Pangan Non Tunai (BPNT) yang dilihat dari Model Implementasi George C. Edwards III yaitu komunikasi, sumber daya, disposisi, dan struktur birokrasi;

\section{Implementasi Program bantuan}

\section{Pangan Non Tunai (BPNT) di}

\section{Kecamatan kuranji}

Sesuai dengan judul dalam penelitian yaitu Implementasi Program Bantuan Pangan Non Tunai (BPNT), penulis ingin melakukan evaluasi terhadap pelaksanaan program ini. Menurut Diansari dalam (Abdullah, 2017) Evaluasi terhadap pelaksanaan kebijakan adalah evaluasi yang digunakanoleh pelaksana kebijakan dalam menentukan tingkat kemajuan dengan rencana yang telah dirancang sebelumny.

Dalam mencapai keefektifan suatu kebijakan yang dilaksanakan, George C. Edwards III dalam (Deddy Mulyadi, 2016) mengemukakan ada 4 (empat) variabel yang mempengaruhi implementasi kebijakan yakni komunikasi, sumberdaya, disposisi, dan struktur birokrasi. Keempat variabel tersebut saling berhubungan antara satu dengan yang lain.

a. Komunikasi

George C. Edwards III dalam (Deddy Mulyadi, 2016) menjelaskan mengenai komunikasi diartikan sebagai penyampaian pesan/informasi kepada kelompok sasaran (target group) sehingga dapat mengurangi distorsi pelaksanaan. Apabila tujuan dan sasaran suatu kebijakan tidak jelas atau bahkan tidak diketahui sama sekali oleh kelompok sasaran, maka kemungkinan akan terjadi resistensi dari kelompok sasaran. George C. Edward III juga menjelaskan dalam (Agustino, 2017)) terdapat tiga hal yang harus dijelaskan mengenai komunikasi variabel komunikasi yaitu :

1) Transmisi

Dalam hal ini transmisi yang dilakukan pemerintah Kota Padang sudah menjalin komunikasi yang baik dengan memberikan informasi semacam surat tertulis Bimbingan Teknis serta pelatihan yang diinformasikan langsung ke Kecamatan, Kecamatan menyosialisasikan kepada Kelurahan-Kelurahan, Kelurahan menyosialisasikan kepada RT/RW yang ada dimasing-masing Kelurahan, dan RT/RW menyosialisasikan kepada masyarakat. Dilihat dari tansmisi dalam pelaksanaan Program BPNT belum baik, karena masih banyak masyarakat Kota Padang yang belum mengetahui program Bantuan Pangan Non Tunai.

2) Kejelasan

Pemerintah Kota Padang sudah memberikan informasi yang jelas dengan memberikan semacam surat tertulis, Bimbingan Teknis serta pelatihan melalui Kecamatan - Kecamatan, Kecamatan menyosialisasikan kepada KelurahanKelurahan, Kelurahan menyosialisasikan kepada RT/RW yang ada dimasing-masing Kelurahan, dan RT/RW menyosialisasikan kepada masyarakat. Kemudian Pemerintah Kecamatan sudah memberikan informasi yang jelas dengan menyosialisasikan Program tersebut dengan mengirim setiap utusan keluaran untuk mengikuti bimbingan teknis maupun pelatihan guna untuk menyampaikan informasi kepada masyarakat lebih baik serta dengan pada 


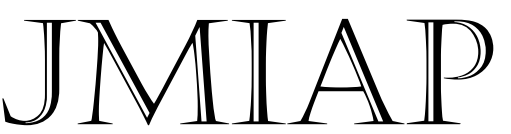

jmiap.ppj.unp.ac.id
Email : jianfis.unp@gmail.com

Vol. 2 No. 1 Maret 2019 saat pertemuan rutin mingguan antara Camat dan Lurah, Kelurahan menyosialisasikan kepada RT/RW yang ada dimasing-masing Kelurahan, dan RT/RW menyosialisasikan kepada masyarakat.

\section{3) Konsisten}

Pemerintah Kota Padang memiliki konsisten yang bagus karena selalu memberikan informasi kepada masyarakat mengenai program BPNT dan program BPNT hingga saat ini masih dijalankan. Pemerintah Kota Padang dalam hal ini dijalankan oleh Dinas Sosial yaitu Bagian Bidang Pemutakhiran Data Fakir Miskin Dinas Sosial Kota Padang, Pemerintah Kecamatan, Pemerintah Kelurahan dan ketua RT/RW belum efektif. Hasil wawancara dengan masyarakat, ditemukan masih banyak masyarakat yang tidak mengenal dan mengetahui adanya pelaksanaan program BPNT.

\section{Sumber Daya}

George C. Edwards III dalam (Sahya Anggaran, 2014) menyatakan bahwa sumber daya merupakan variabel kedua dalam implementasi kebijakan. Varibael tersebut tidak hanya melingkupi fktor sumber dya manusia/aparat saja, juga melingkupi kemampuan sumber daya materil lainnya untuk mendukung pelaksanaan kebijakan. Walaupun isi kebijakan tersebut sudah dikomunikasikan secara jelas dan konsisten, tetapi apabila masih ada implementor kekurangan sumber daya untuk melaksanakan kebijakan, maka implementasi kebijakan tidak akan berjalan dengan efektif.

Selanjutnya Sumber daya manusia dalam pelaksanaan Program BPNT, aparat yang terlibat dalam pelaksanaan program BPNT adalah Walikota, Dinas Sosial, Bank penyalur, Camat, Kelurahan, tenaga pendamping dan RT/RW. Kemudian aparat yang terlibta pada tingkat kelurahan masih sedikit sumber daya anggota dari
Kelurahan yang terlibat dalam menyosialisasikan program santunan kematian kepada RT/RW dan masyarakat. Dilihat dari sumber daya manusia dalam pelaksanaan Program BPNT belum memadai, karena aparat dari Kelurahan belum ikut serta dalam pelaksanaan Program Bantuan Pangan Non Tunai.

\section{Disposisi}

Karakteristik disposisi yang menempel erat kepada implementor adalah kejujuran, komitmen dan demokratis. Seorang Implementor harus memiliki komitmen tinggi dan jujur bisa bertahan diantara hambatan yang ditemui dalam pelaksanaan program/kebijakan. Kemudian Kejujuran dapat mengarahkan seorang implementor agar tetap berada dalam arah program yang telah ditetapkan dalam guideline program. Komitmen dan kejujuran dapat membawa seorang implementor semakin antusias dalam melaksanakan tahap-tahap program secara konsisten. Kemudian Sikap yang demokratis dapat meningkatkan kesan baik seorang implementor sehingga kebijakan berjalan baik dihadapan anggota kelompok sasaran. Sikap ini tentunya dapat menurunkan resistensi dari masyarakat dan menumbuhkan rasa percaya dan kepedulian kelompok sasaran terhadap seorang implementor program/kebijakan.

Disposisi Pemerintah Kota Padang dalam pelaksanaan Program BPNT kurang baik, karena tidak adanya keinginan dari pemerintah dalam mengoptimalkan pelaksanaan program BPNT, sesuai dengan permasalahan pada saat wawancara, masih ada ditemukan Kelurahan dan masyarakat yang belum mengetahui program BPNT. Berdasarkan hasil penelitian Asyiah (2017) tentang Evaluasi Implementasi Kebijakan Pendidikan Gratis di Kabupaten Pasaman bahwa Implementasi Peraturan Daerah Kabupaten Pasaman No.2 Tahun 2013 tentang pendidikan gratis, dari segi disposisi, komitmen pelaksana dalam pelaksanaan pendidikan gratis di 
Kabupaten Pasaman masih kurang baik, karena masih ada ditemukan sekolah yang meminta iuran/pungutan kepada orang tua siswa. Menurut George C. Edwards III dalam (Abdullah, 2017) mengatakan bahwa disposisi merupakan hal ketiga dalam implementasi kebijakan.

b. Struktur Birokrasi

Struktur birokrasi dalam pelaksanaan Program BPNT cukup jelas, yaitu Walikota Padang, Wakil Walikota Padang, Dinas Sosial, Pemerintah Kecamatan, Pemerintah Kelurahan, RT/RW. Tetapi Kelurahan belum bisa terlibat penuh dalam pelaksanaan program BPNT dikarenaka terlalu berbelitnya prosedur untuk mengurus bantuan, masyarakat diharuskan menunggu serta data masyarakat yang tidak valid dalam memverifikasi data, jarak masyarakat pinggir Kota Padang ke Kelurahan, Kemcamatan Atau Dinas Sosial untuk mengurus bantuan terlalu jauh sehingga memakan biaya dan waktu yang cukup banyak. Menurut hasil penelitian (Reza, 2015) tentang Evaluasi Kebijakan Penanggulangan Kemiskinan Pemerintah Kota Balikpapan, dalam merealisasi pelaksanaan program kebijakan penanggulangan kemiskinan di Kota Balikpapan masih sangat jauh dari kata berhasil. Hal ini disebabkan banyak ditemui beberapa kekurangan dan beberapa kendala dalam pelaksanaannya. Diantaranya, penggunaan bantuan pelayanan kesehatan oleh warga miskin yang kurang paham akan perosedural bantuan layanan kesehatan secara umum dan asuransi kesehatan saat ini (BPJS). George C. Edwards III dalam (Deddy Mulyadi, 2016) menyatakan bahwa dalamstruktur birokrasi yang menjadi hal penting adalah pelaksanaan kebijakan yang mencakup seluruh mekanisme dan struktur organisasi pelaksana kebijakan. Dalam Struktur organisasi yang bertugas melaksanakan kebijakan harus memiliki pengaruh yang sangat signifikan terhadap pelaksanaan kebijakan. Ada beberapa aspek dari aspek struktur yang penting dari setiap organisasi adalah adanya prosedur operasi yang standar (SOP). SOP dapat menjadi pedoman untuk bagi setiap implementor dalam bertindakmenjalankan tugasnya.

Menurut penelitian (Reza, 2015), dapat penelitian iimpulkan bahwa struktur birokrasi/standard operating procedures (SOP) dalam implementasi Kebijakan kurang baik. standard operating procedures (SOP) dianggap sangat penting karena merupakan panduan kerja atau teknis dalam melakukan kegiatan atau pekerjaan dalam suatu organisasi.

Faktor - faktor yang mempengaruhi implementasi Program Bantuan Pangan Non Tunai (BPNT) di Kecamatan Kuranji Kota Padang

Pada bagian ini penulis melihat ada beberapa point penting yang patut dipaparkan. Yaitu; faktor - faktor yang memengaruhi petugas dalam implementasi program BPNT. Faktor - faktor tersebut penulis kelompokkan menjadi faktor internal dan faktor eksternal. Penulis menilai, adapun faktor internal dan faktor juga tidak luput dari hasil deskripsi implementasi yang penulis jelaskan sebelumnya. Artinya hasil diskripsi implementasi yang penulis jelaskan diatas juga termasuk bagian dari faktor internal dan eksternal yang mempengaruhi kelancaran implementasi.

\section{a. Faktor Internal}

Beberapa Hambatan yang menjadi kendala oleh kota Padang tidak hanya bersumber dari masyarakat melainkan pemeruntahan itu sendiri, seperti keterbatasan baik secara kuantitas maupun kualitas sumber daya dari personil aparatur negeri sipil (ASN) serta tenaga pendamping dalam mengimplementasikan program BPNT. Hal ini dikategorikan sebagai faktor 


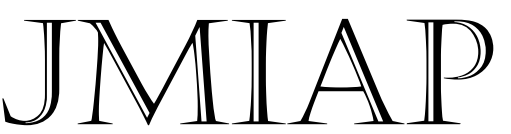

jmiap.ppj.unp.ac.id
Email : jianfis.unp@gmail.com Vol. 2 No. 1 Maret 2019 penghambat karena dengan buruknya kualitas ASN maka dapat mempengaruhi jalannya implementasi program BPNT di Kecamatan Kuranji Kota Padang.

\section{b. Faktor Eksternal}

Rendahnya pemahaman masyarakat mengenai program BPNT khususnya masyarakat sebagai penerima bantuan membuat masyarakat banyak yang tidak mengetahi adanya program BPNT. Kemudian banyak penerima bantuan yang hanya sekedar mendapat bantuan tapi tidak mengetahui cara pengambilan bantuan. Hal ini juga didukung oleh faktor lain seperti banyaknya penerima bantuan yang data salah, tidak valid, meninggal dunia dan berdomisili di tempat lain atau pindah. Ini semua mengakibatkan jalannya program BPNT ditengah masyarakat tidak berjalan dengan baik melainkan sebagai pengahambat.

\section{Solusi dalam mengatasi kendala - kendala dalam pengimplementasian program Bantuan Pangan Non Tunai (BPNT) di Kecamatan Kuranji Kota Padang}

Untuk mengetahui semua kendala yang terjadi dalam pengimplementasian progam BPNT di Kecamatan Kuranji diperlukan upaya yang tepat sehingga semua kendala tersebut bisa diatasi dengan semestinya dan pelaksanaan program bisa maksimaldan tujuan untuk mensejahterakan masyarakat bisa terwujud. Adapun upaya yang dilakukan oleh Dinas Sosial yaitu :

Pertama, Untuk meningkatkan kesadaran dan pengetahuan pengetahuan masyarakat mengenai program BPNT maka pihak dinas dan pihak terkait tidak henti-hentinya memberikan pemahaman dan pembinaan melalui penyuluhan kepada masyarakat secara rutin sehingga pemahaman akan meningkatnya kesejahteraan keluarga penerima manfaat terhadap bantuan yang diterima tersebut dapat pergunakan dengan sebaik-baiknya. Selain itu pihak terkait dapat melakukan pengawasan dan peninjauan ke masyarakat mengenai pelaksanaan program BPNT ini serta melakukan evaluasi terhadap kelemahan yang terjadi dalam pelaksanaan program tersebut.

Memberikan informasi secara berkala kepada masyarakat merupakan upaya untuk meningkatkan kesadaran keluarga penerima manfaat lebih memahami bagaimana cara dan proses dalam penyaluran BPNT. Sehingga masyarakat lebih bisa merasakan manfaat dari program tersebut. Memberikan informasi kepada masyarakat secara berkala juga berkaitan dengan para petugas dan tenaga pendamping yang meninformasikan kepada masyarakat. Hal ini berkaitan dengan sejauh mana komunikasi petugas menyampaikan informasi kepada masyarakat. Ini semua juga bisa menilai apakah program tersebut sampai kemasyarakat secara penuh

Kedua, Untuk mengatasi kendala dalam pembagian dan penyaluran bantuan ke keluarga penerima manfaat atau masyarakat, pihak dinas melakukan pengawasan secara intensif dan langsung melibatkan diri serta lebih meningkatkan sosialisasi program kepada masyarakat, sehingga informasi tentang program bisa tersampaikan ke seluruh masyarakat.

\section{KESIMPULAN}

Pertama, Implementasi Program Bantuan Pangan Non Tunai belum dapat dijalankan sesuai SOP yang ada dikarena masih ada masyarakat yang tidak memahami program BPNT. Hal ini dapat dilihat dari komunikasi antara Pemerintah Kecamatan dengan Kelurahan belum berjalan dengan baik 
maka berpengaruh kepada pelaksanaan Program BPNT sehingga tujuan yang hendak dicapai tidak dapat tercapai secara maksimal;

Kedua, Sumber Daya, terdapat kendala yaitu pada sumber daya anggota yaitu ditemukan bahwa aparat dari Kelurahan serta Tenaga Pendamping belum terlibat dalam pelaksanaan Program BPNT. Maka dari itu itu jika dikaitkan dengan permasalahan yang ada seperti sumber daya anggota yang ada belum memadai Ketiga,
Disposisi, disposisi petugas dalam pelaksanaan Program BPNT masih kurang baik, karena belum adanya keinginan dari pemerintah terutama pemerintahan Kelurahan dalam mengoptimalkan pelaksanaan program BPNT.

Keempat, Struktur Birokrasi, prosedur pelayanan dan struktur organisasi dalam pelaksanaan Program BPNT cukup rumit. 


\section{Daftar Pustaka}

\section{Buku:}

Abdullah, R. (2017). Konsep Umum Pelaksanaan Kebijakan Publik. Jurnal Publik, 11, 1-12.

Agustino, L. (2017). Dasar-Dasar Kebijakan Publik. Bandung: Alfabeta.

Deddy Mulyadi. (2016). Studi Kebijakan Publik dan Pelayanan Publik. Bandung: CV Alfabeta.

Reza, F. (2015). Evaluasi Kebijakan Penanggulangan Kemiskinan Pemerintah Kota Balikpapan. Jurnal Imu Sosial Dan Ilmu Politik, 4.

Sahya Anggaran. (2014). Kebijakan Publik. Bandung: CV Pustaka Setia.

Wahab, S. A. (2015). Analisis Kebijakan. Jakarta: Bumi Aksara.

Winarno, B. (2007). Kebijakan Publik: Teori dan Proses. Jakarta: Media Pressindo.

\section{Dokumen}

Peraturan Presiden (Perpres) Nomor 63 Tahun 2017 Tentang Penyaluran Bantuan Sosial Secara Non Tunai

Pedoman Umum (Pedum) Bantuan Pangan Non Tunai 2018
Undang-undang No.25 Tahun 2009 tentang Pelayanan Publik

Keputusan MENPAN No.63/KEP/ M. PAN/ 7/2003

Keputusan Mentri Sosial Republik Indonesia No.132/HUK/2017 tentang Penetapan Wilayah Kerja Program Bantuan Sosial Pangan Dilingkungan Direktorat Jendral Penanganan Fakir Miskin

Keputusan Mentri Sosial Republik Indonesia No.339/HUK/2016 tentang Penetapan Jumlah Keluarga Penerima Manfaat Tahun 2017

Keputusan Direktur Jendral Penanganan Fakir Miskin No.5/PFM/SK/HK.01/07/2017

Keputusan Gubernur Sumatera Barat No.500-258-2017 Tentang Penetapan Pagu Keluarga Penerima Manfaat Beras Sejahtera dan Bantuan Pangan Non Tunai Per Kabupaten/Kota DI Provinsi Sumatera Barat Tahun 2017

Peraturan Direktur Jendral Penanganan Fakir Miskin No. 06/4/PER/HK.01/08/2018 Tentang Petunjuk Teknis Mekanisme Penyaluran Bantuan Pangan Non Tunai 